\title{
(-) \\ OPEN ACCESS \\ The contribution of joint and skin improvements to the health-related quality of life of patients with psoriatic arthritis: a post hoc analysis of two randomised controlled studies
}

\author{
Arthur Kavanaugh, ${ }^{1}$ Alice Gottlieb, ${ }^{2}$ Akimichi Morita, ${ }^{3}$ Joseph F Merola, ${ }^{4,5}$ \\ Chen-Yen Lin, ${ }^{6}$ Julie Birt, ${ }^{6}$ Catherine L Shuler, ${ }^{6}$ Matthew M Hufford, ${ }^{6}$ Diamant Thaçi ${ }^{7}$
}

\begin{abstract}
Handling editor Josef $S$ Smolen

- Additional material is published online only. To view, please visit the journal online (http://dx.doi.org/10.1136/ annrheumdis-2018-215003)
\end{abstract}

For numbered affiliations see end of article.

Correspondence to Professor Arthur Kavanaugh, University of California, San Diego, La Jolla, USA; akavanaugh@ucsd.edu

Some of these results were previously presented as a poster presentation at the 2017 Annual Meeting of the American College of Rheumatology.

Received 31 December 2018 Revised 30 April 2019 Accepted 2 May 2019 Published Online First 21 May 2019

\section{Check for updates}

(C) Author(s) (or their employer(s)) 2019. Re-use permitted under CC BY-NC. No commercial re-use. See rights and permissions. Published by BMJ.

To cite: Kavanaugh $A$,

Gottlieb A, Morita A,

et al. Ann Rheum Dis

2019;78:1215-1219.

\section{ABSTRACT}

Objective Determine the contribution of joint and skin improvements to health-related quality of life (HRQoL) in patients with psoriatic arthritis (PSA).

Methods SPIRIT-P1 and SPIRIT-P2 are phase 3 trials investigating ixekizumab, an interleukin-17A antagonist, in the treatment of patients with active PsA. Patients were randomised to ixekizumab or placebo. Outcomes included the Disease Activity Index for Psoriatic Arthritis (DAPSA), the Psoriasis Area and Severity Index (PASI), the European Quality of Life-Five Dimensions (EQ-5D) Visual Analogue Score (VAS), the 36-Item Short-Form Health Survey (SF-36) and the Work Productivity and Activity Impairment (WPAI) Questionnaire. The contribution of joint and skin improvements to HRQoL was modelled using a smoothing spline method and depicted with response surface graphics.

Results In this integrated analysis, 402 patients with PsA had baseline psoriasis of $\geq 3 \%$ of body surface area. We applied response surface modelling to this patient data set to investigate the relationship between DAPSA, PASI and HRQoL improvements at week 24. The greatest improvement in EQ-5D VAS was associated with the largest per cent improvements in both DAPSA and PASI together, rather than DAPSA or PASI alone. Similar observations were made in domains of SF-36 and WPAI. Conclusion Optimal improvements in patients' HRQoL were dependent on successful treatment of both joint and skin symptoms.

\section{INTRODUCTION}

Psoriatic arthritis (PsA) is a chronic immune-mediated inflammatory disease involving articular and extra-articular symptoms, particularly psoriasis $(\mathrm{PsO}) .{ }^{1}$ Of note, health-related quality of life (HRQoL) impairment in PsA is similar to rheumatoid arthritis (RA), even though patients with PsA may have, on average, fewer joints involved as compared with those with RA, and may relate to the additional burden of skin PsO and other domains of disease..$^{2-7}$ While current disease-modifying antirheumatic drugs (DMARDs) can have varying success in treating the differing manifestations of PsA, it is currently unclear to what degree treating joint and/or skin symptoms in PsA correlates with improvements in patients' HRQoL. In this post hoc analysis, we leveraged clinical trial data from SPIRIT-P1 and SPIRIT-P2, ${ }^{8} 9$ which investigated

\section{Key messages}

What is already known about this subject?

- Health-related quality of life (HRQoL) impairment in patients with psoriatic arthritis (PsA) can be significant, similar in extent to patients with rheumatoid arthritis. The presence of plaque psoriasis, in addition to arthritis, is thought to be a significant contributor to overall morbidity in patients with PsA.

- While current therapies can have varying success in treating the differing manifestations of PsA, it is currently unclear to what degree treating joint and/or skin symptoms in PsA correlates with improvements in patients' HRQoL.

What does this study add?

- Leveraging data from clinical trials in PsA, improvements in joint symptoms were pivotal in improving overall patient HRQoL. However, improvements in both joint and skin manifestations were necessary to achieve optimal patient HRQoL improvements in both physical and mental domains.

How might this impact on clinical practice or future developments?

- The results of this study indicate that treatment regimens that effectively treat patient joint and skin symptoms should be considered to achieve optimal improvements in overall HRQoL.

the interleukin-17A antagonist ixekizumab for the treatment of PsA, to assess the contributions of joint and skin symptom improvements on patients' HRQoL.

\section{METHODS}

\section{Study design and patient population}

Data within this integrated post hoc analysis were derived from SPIRIT-P1 (NCT01695239) and SPIRIT-P2 (NCT02349295). The study design and patient populations for each study have been described previously. ${ }^{89}$ Briefly, the SPIRIT studies are phase 3 double-blind, placebo-controlled clinical trials involving patients with active PsA. In SPIRIT-P1, the patient population was biologic 
DMARD-naive. In SPIRIT-P2, patients must have had an inadequate response or intolerance to TNF inhibitors. In both trials, enrolled patients had $\geq 3$ of 68 tender joint and $\geq 3$ of 66 swollen joint counts and had an active or documented history of PsO at study entry.

Patients were randomised to placebo (until week 24) or ixekizumab $80 \mathrm{mg}$ once every 4 or 2 weeks. At week 16, patients deemed inadequate responders were required to add/modify medications. In these analyses, patients were included regardless of the treatment group.

\section{Outcomes}

Improvements in joint and skin symptoms were measured as percent improvement from baseline by Disease Activity Index for Psoriatic Arthritis (DAPSA) and Psoriasis Area and Severity Index (PASI) scores, respectively. ${ }^{10} 11$ DAPSA is a composite measure incorporating swollen and tender joints, function, pain and disease activity, but does not directly measure $\mathrm{PsO}$ skin symptoms. ${ }^{11}$ Improvements in HRQoL were measured as change from baseline (CFB) by the following instruments: European Quality of Life-Five Dimensions (EQ-5D) Visual Analogue Score (VAS), activity impairment domain of the Work Productivity and Activity Impairment (WPAI) Questionnaire ${ }^{12}$ and 36-Item ShortForm Health Survey (SF-36). ${ }^{13}$

\section{Statistical analyses}

Post hoc analyses were conducted on all ixekizumab-treated and placebo-treated patients with a baseline $\mathrm{PsO}$ of $\geq 3 \%$ or $\geq 10 \%$ body surface area (BSA) from the integrated data set. Missing data were imputed with the last observation carried forward. For patients classified as inadequate responders at week 16, data for week 24 were imputed from the week 16 time point.

The combined effects of joint and skin improvements on HRQoL were modelled using the smoothing spline method (both as CFB). ${ }^{14}$ HRQoL was assumed to be a smooth function of joint and skin symptoms without imposing specific functional form. The smooth function was expressed as a linear combination of a collection of basis functions. The degree of smoothness was controlled by an additional parameter to avoid overfitting. The unknown parameters involving the basis function can be solved efficiently using ridge regression techniques, whereas the smoothing parameter is selected using restricted marginal likelihood. This analysis was conducted using R V.3.3.3 with the general smoothing splines (gss) package (V.2.1-7 or later).

\section{Results}

We investigated the relationship between improvements in joint and skin symptoms at week 24 on patients' HRQoL using integrated results from the SPIRIT trials for 402 patients with active PsA and BSA $\geq 3 \%$ (including 224 patients with $\mathrm{BSA} \geq 10 \%$ ) at baseline (table 1). Joint involvement was similar in the BSA $\geq 3 \%$ and $\mathrm{BSA} \geq 10 \%$ groups. Smoothing spline modelling was performed and a colour spectrum was applied to HRQoL improvements (figure 1A,B).

In models with EQ-5D VAS, HRQoL improvements were highest (33.1 CFB) when patients achieved 100\% improvement in both DAPSA and PASI scores (figure 2). Joint symptom improvement alone (ie, 100\%/0\% DAPSA/PASI improvements) yielded a 17.7 CFB improvement. while skin symptom clearance alone (ie, 0\%/100\% DAPSA/PASI improvements) yielded a -1.2 CFB improvement. In patients with $\geq 10 \%$ BSA, a greater dependence on skin symptom improvement was necessary to achieve optimal EQ-5D VAS scores (figure 2). Similar results
Table 1 Baseline characteristics of patients with baseline $\geq 3 \%$ BSA and $\geq 10 \%$ BSA

\begin{tabular}{|c|c|c|}
\hline & \multicolumn{2}{|c|}{ SPIRIT Trial Integrated Database } \\
\hline & $\geq 3 \%$ BSA $(n=402)^{*}$ & $\geq 10 \%$ BSA $(n=224) \dagger$ \\
\hline Age, years & $49.8(11.6)$ & $49.1(11.7)$ \\
\hline Male & $206(51.2 \%)$ & $131(58.5 \%)$ \\
\hline Weight, kg & $87.8(21.4)$ & $88.4(21.8)$ \\
\hline $\mathrm{BMI}, \mathrm{kg} / \mathrm{m}^{2}$ & $30.5(7.4)$ & $30.2(7.4)$ \\
\hline \multicolumn{3}{|l|}{ Race } \\
\hline White & $369(92.0 \%)$ & $199(89.2 \%)$ \\
\hline Asian & $22(5.5 \%)$ & $18(8.1 \%)$ \\
\hline Other & $10(2.4 \%)$ & $6(2.7 \%)$ \\
\hline $\begin{array}{l}\text { Time since psoriatic arthritis } \\
\text { diagnosis, years }\end{array}$ & $8.6(7.9)$ & $8.7(7.6)$ \\
\hline $\begin{array}{l}\text { Time since psoriasis diagnosis, } \\
\text { years }\end{array}$ & $16.9(12.6)$ & $17.5(12.4)$ \\
\hline CDMARD current use & $226(56.2 \%)$ & $122(54.5 \%)$ \\
\hline Methotrexate current use & $188(46.8 \%)$ & $104(46.4 \%)$ \\
\hline Prior TNFi experience & $203(50.5 \%)$ & $106(47.3 \%)$ \\
\hline \multicolumn{3}{|l|}{ Baseline disease scores } \\
\hline Tender joint count, 68 joints & $22.1(15.0)$ & $22.3(14.9)$ \\
\hline $\begin{array}{l}\text { Swollen joint count, } 66 \\
\text { joints }\end{array}$ & $11.9(8.6)$ & $11.8(8.0)$ \\
\hline $\mathrm{CRP}, \mathrm{mg} / \mathrm{L}$ & $16.7(27.2)$ & $17.5(27.6)$ \\
\hline DAPSA score & $48.7(22.6)$ & $49.0(22.0)$ \\
\hline$\%$ BSA of psoriasis $\ddagger$ & $18.3(18.5)$ & $28.7(19.1)$ \\
\hline PASI total score & $8.5(8.3)$ & $12.0(9.3)$ \\
\hline \multicolumn{3}{|l|}{ Baseline quality of life scores } \\
\hline DLQI total score & $8.7(6.9)$ & $9.8(7.2)$ \\
\hline EQ-5D VAS score & $52.5(21.0)$ & $51.5(20.9)$ \\
\hline \multicolumn{3}{|l|}{ SF-36 domain scores } \\
\hline Bodily pain & $37.9(19.7)$ & $38.5(20.4)$ \\
\hline General health & $44.6(19.3)$ & $44.5(19.4)$ \\
\hline Mental health & $64.4(21.8)$ & $64.2(21.6)$ \\
\hline Physical functioning & $41.8(26.2)$ & $42.6(26.2)$ \\
\hline Role emotional & $71.7(27.0)$ & $72.7(26.8)$ \\
\hline Role physical & $43.9(25.0)$ & $44.1(25.4)$ \\
\hline Social functioning & $63.3(27.4)$ & $64.7(27.7)$ \\
\hline Vitality & $40.6(21.8)$ & $41.7(21.1)$ \\
\hline WPAl-activity impairment & $53.0(25.3)$ & $50.7(24.9)$ \\
\hline
\end{tabular}

Data presented are mean (SD) or $\mathrm{n}(\%)$.

*Placebo: $n=134$, ixekizumab: $n=268$.

†Placebo: $n=68$, ixekizumab: $n=156$.

¥BSA severity ratings: $<3 \%=$ mild, $3 \%-10 \%=$ moderate, $>10 \%=$ severe. $\mathrm{BMI}$, body mass index; $\mathrm{BSA}$, body surface area; CDMARD, conventional diseasemodifying antirheumatic drug; CRP, C reactive protein; DAPSA, Disease Activity Index for Psoriatic Arthritis; DLQI, Dermatology Life Quality Index; EQ-5D, European Quality of Life-Five Dimensions; PASI, Psoriasis Area and Severity Index; SF-36, 36-Item Short-Form Health Survey; TNFi, TNF inhibitor; VAS, Visual Analogue Score; WPAI, Work Productivity and Activity Impairment.

were observed in models with the activity impairment domain of WPAI (online supplementary figure S1). When the models were adjusted for age, gender and biologic experience as covariates, similar results were also observed (data not shown).

In models incorporating all SF-36 domains, improvement in joint symptoms alone yielded achievement of minimally clinically important difference (MCID) ( $\geq 5$ improvement) in all domains in patients with $\geq 3 \%$ BSA; however, when skin symptom improvements were also present, less joint symptom improvement was needed to achieve MCIDs for the domains (except vitality) with general health and social functioning particularly 
A.

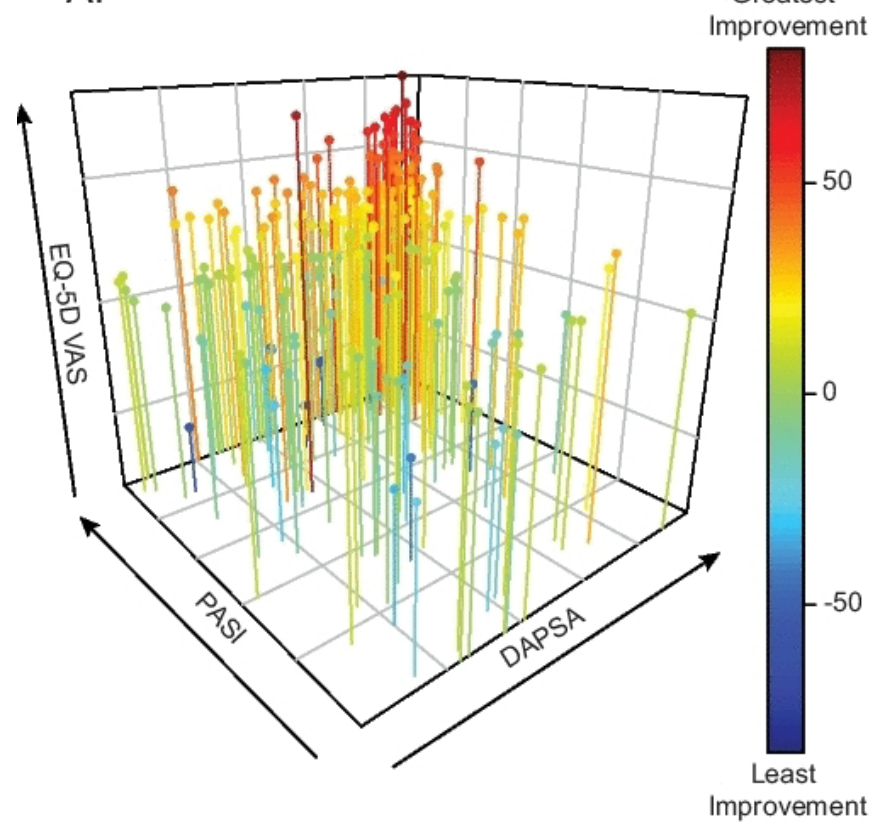

B.

Greatest Improvement

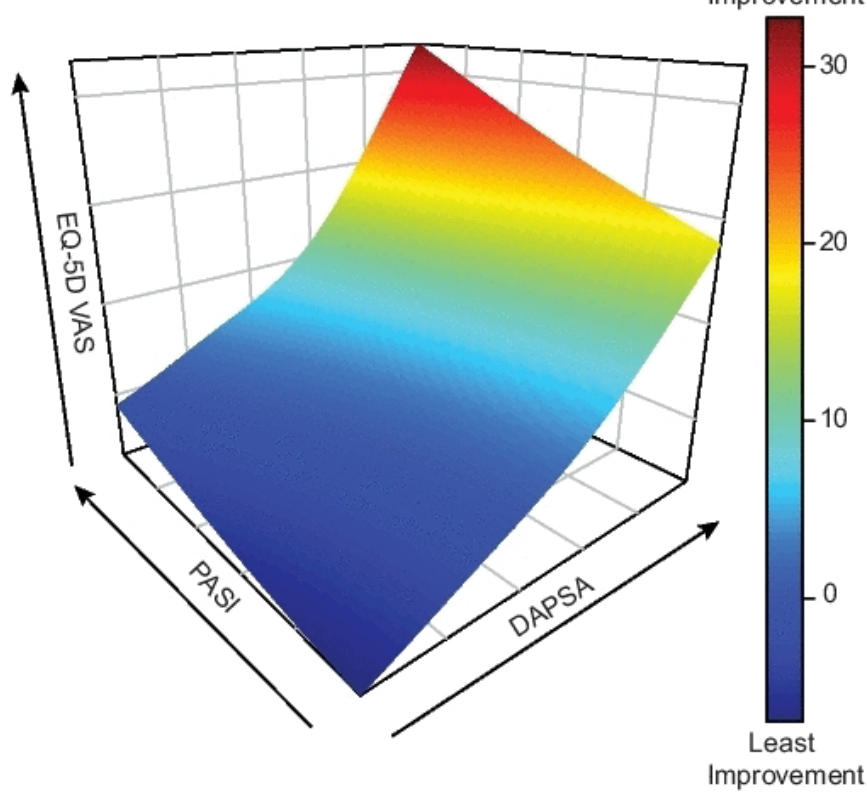

Figure 1 Response surface modelling. (A) Three-dimensional scatterplot and (B) response surface of scatterplot estimated by smoothing spline method of skin (y-axis, PASI-percent improvement), joint (x-axis, DAPSA—percent improvement) and HRQoL (z-axis, EQ-5D—change from baseline) improvement at week 24. A colour spectrum is applied to health-related quality of life (blue (least improvement) to red (greatest improvement)). DAPSA, Disease Activity Index for Psoriatic Arthritis; EQ-5D, European Quality of Life-Five Dimensions; PASI, Psoriasis Area and Severity Index; VAS, Visual Analogue Score.

dependent on skin symptom resolution (online supplementary Figure S2A). The greatest improvements were observed across all domains, except bodily pain, when both joint and skin symptoms improved.

In patients with $\geq 10 \% \mathrm{BSA}$, the necessity of skin symptom improvement increased for general health, social functioning, bodily pain, and vitality (online supplementary Figure S2B). In contrast, improvement in joint symptom alone was sufficient for optimal improvements in mental health and role emotional, which also exhibited the smallest CFB at week 24 in the modelling.

\section{Discussion}

We leveraged data from two phase 3 clinical trials to model the relative impact of joint and skin improvements on HRQoL in patients with active PsA and $\mathrm{PsO}$. As measured by non-disease-specific patient-reported outcome (PRO) measures, improvements
A.

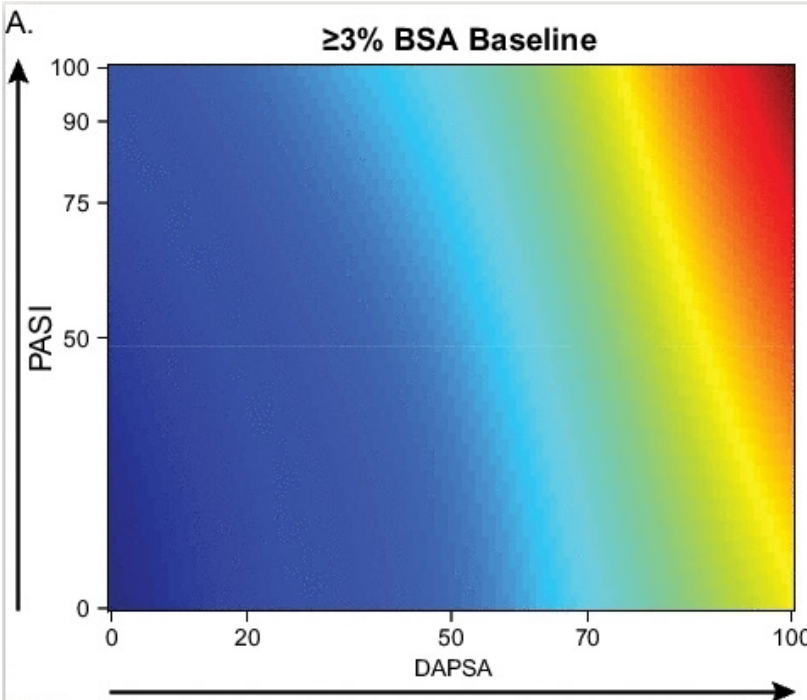

B.

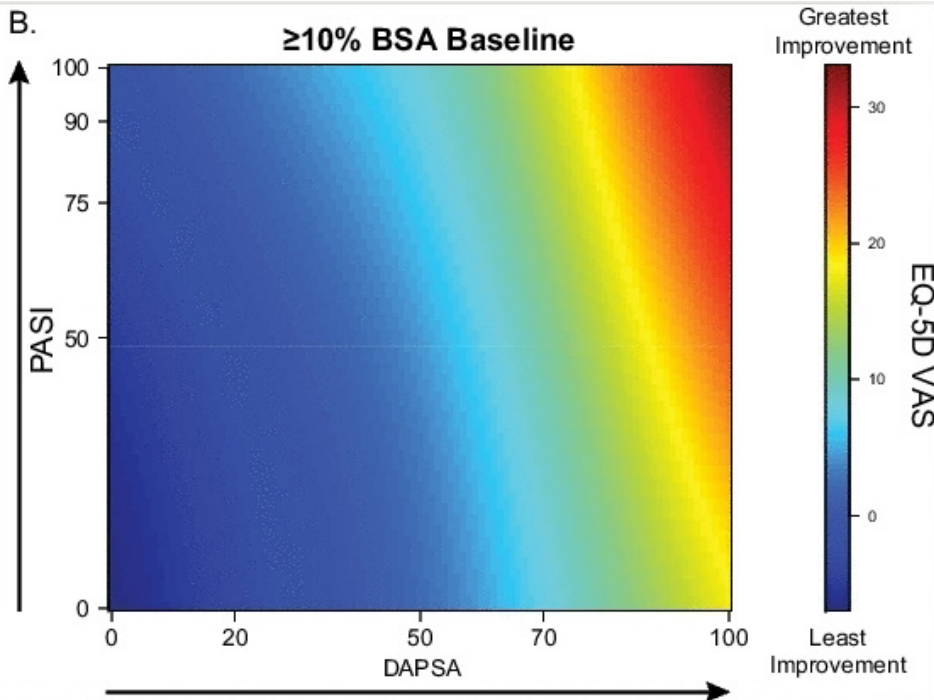

Figure 2 Impact of joint and skin improvements on patient health-related quality of life as measured by EQ-5D VAS. Heat maps depict change from baseline in EQ-5D VAS at week 24, with a range from least improvement (blue) to greatest improvement (red). Joint and skin improvements measured by per cent improvements from baseline DAPSA and PASI scores at week 24, respectively. Patients with baseline psoriasis of $\geq 3 \%$ (A) and $\geq 10 \%$ BSA (B) are depicted in the left and right panels, respectively. BSA, body surface area; DAPSA, Disease Activity Index for Psoriatic Arthritis; EQ-5D, European Quality of Life-Five Dimensions; PASI, Psoriasis Area and Severity Index; VAS, Visual Analogue Score. 
in joint symptoms were a larger driver of improvements in patient HRQoL than those for PsO. However, improvements in both joint and skin manifestations are necessary to achieve optimal patient HRQoL levels.

In the models built with patients with greater $\mathrm{PsO}$ involvement at baseline ( $\geq 10 \% \mathrm{BSA}$ ), skin symptom improvement was more prominent in positively affecting the scores of EQ-5D VAS, WPAI-activity impairment domain, and four of eight domains of SF-36. Importantly, the levels of tender and swollen joints and DAPSA scores were similar between patients with baseline $\mathrm{PsO}$ of $\geq 3 \%$ and BSA of $\geq 10 \%$. Collectively, these data indicate that the relative contribution of skin improvement to improvements in HRQOL is dependent, to a degree, on the level of PsO at initiation of treatment.

In two domains of SF-36 (mental health and role emotional), there was less dependence on skin improvements to achieve HRQoL improvements in the models built with data from patients with baseline PsO of $\geq 10 \%$ BSA. Reasons for this observation are unclear as PASI responses have been previously associated with improvement in the mental aspects of HRQoL in patients with PsA. ${ }^{15} 16$ These two particular domains exhibited the smallest overall improvements at week 24. Coupled with fewer patients with baseline $\mathrm{PsO}$ of $\geq 10 \%$ BSA, pattern estimates could have been more greatly influenced by fewer subjects within certain regions of the model.

Previous clinical trials have investigated the relative impact of improvements in joint and skin symptoms on PROs. ${ }^{15} 16$ Collectively, the studies demonstrated that the greatest improvements in HRQoL were achieved when patients achieved clinically significant improvements in both joint and skin symptoms, particularly with respect to the mental aspects of the disease (eg, SF-36 MCS). Improvements in the physical aspects of the disease (eg, SF-36 PCS) were more strongly associated with joint symptom improvement.

The analyses presented here demonstrate that HRQoL improvements, measured by SF-36 domains, as well as the EQ-5D VAS and WPAI domains, require both joint and skin improvements for optimal responses. These analyses differ from previous disclosures, in part, by examining the correlation of a response rather than the ability of a patient to achieve a response. ${ }^{15} 16$ With current therapies, it may be possible for patients to achieve higher clinical efficacy benchmarks than those previously considered standard (eg, PASI75 and American College of Rheumatology response criteria with 20\% improvement (ACR20)). Using our methods herein, we were able to predict the impact of reaching higher efficacy thresholds on patient HRQoL. In addition, previous reports examined only patients treated with TNF inhibitors. We applied the relative efficacy improvements from both placebo-treated and ixekizumab-treated patients to our model.

To measure joint symptom improvement, we utilised DAPSA, which incorporates PROs. Considering that we employed PRO to measure patient HRQoL, this could potentially lead to some bias. Therefore, we also measured joint symptom improvement using either tender or swollen joint counts. Both of these models also suggest that improvements in both joint and skin manifestations are necessary to achieve optimal patient HRQoL levels (online supplementary figures S3 and S4).

There are limitations to our analyses. Relatively smaller numbers of patients have joint symptom improvement alone than those of patients having skin symptom improvement alone. However, the wide distribution of joint and skin improvements still allows coverage of the entire spectrum without extrapolating the result beyond what was observed. DAPSA and PASI, as measures in themselves, cannot fully capture the extent of PsA severity. DAPSA does not directly assess periarticular domains of PsA (enthesitis and dactylitis), while PASI does not necessarily account for difficult-to-treat locations of PsO (eg, genital, palms and nails). Future analyses incorporating these domains, which can influence HRQoL, would provide additional insight. Lastly, the interpretation of these analyses was limited to patients with PsA with $\mathrm{PsO}$ of $\geq 3 \%$ BSA as reliable assessment of PsO activity becomes problematic in patients with less extensive disease. It is therefore unclear to what extent these results are applicable to patients with milder $\mathrm{PsO}$.

In summary, using clinical trial data, we demonstrated that improvements in both joint and skin manifestations are necessary for optimal HRQoL in patients with active PsA and PsO. Therefore, therapies targeting both joint and skin symptoms should be preferred to achieve optimal improvements in overall quality of life.

\section{Author affiliations}

'Department of Medicine, School of Medicine, University of California, San Diego, La Jolla, California, USA

${ }^{2}$ Department of Dermatology, Icahn School of Medicine at Mt. Sinai, New York, New York, USA

${ }^{3}$ Department of Geriatric and Environmental Dermatology, Nagoya City University Graduate School of Medical Sciences, Nagoya, Japan

${ }^{4}$ Department of Medicine, Division of Rheumatology, and Department of Dermatology, Harvard Medical School, Boston, Massachusetts, USA

${ }^{5}$ Department of Medicine, Division of Rheumatology, and Department of Dermatology, Brigham and Women's Hospital, Boston, Massachusetts, USA

${ }^{6}$ Lilly Research Labs, Eli Lilly and Company, Indianapolis, Indiana, USA

${ }^{7}$ Comprehensive Center of Inflammation Medicine, University Hospital SchleswigHolstein Campus, Luebeck, Germany

Acknowledgements The authors thank Brian S Comer, PhD, and David W Mcllwain, PhD, for medical writing support, and Prashant Raj Kumar, BPT, and Julie Sherman for editorial assistance during the development of the manuscript. All are employees of Eli Lilly and Company.

Contributors AK contributed to the acquisition of data and the analysis and interpretation of the study results. AG and CYL contributed to the conception of the work and the analysis and interpretation of the study results. AM and JFM contributed to the analysis and interpretation of the study results. JB contributed to the design of the study and the interpretation of study results. CLS contributed to the acquisition and interpretation of the study results. MMH contributed to the conception of the work, the design of the study, and the analysis and interpretation of the study results. DT contributed to the acquisition, analysis and interpretation of the study results. All authors contributed to the critical revisions and approved the final version of the manuscript.

Funding This project was supported by Eli Lilly and Company.

Competing interests AK has been a consultant for Eli Lilly and Company. AG has received consulting or advisory board honoraria, speaking honoraria and/or grants from Abbvie, BMS, Celgene Corporation, Dermira, Eli Lilly and Company, Incyte Corporation, Janssen Biotech, Janssen-Ortho, LEO Pharma, US, Lilly ICOS LLC, Novartis, Sun Pharmaceuticals and UCB. AM has received grant support and lecture fees from AbbVie, Esai, Kyowa Hakko Kirin, Leo Pharma, Maruho, Mitsubishi Tanabe Pharma, Novartis and Torii Pharmaceutical and lecture fees from Celgene, Eli Lilly Japan and Janssen Pharmaceutical. JFM has received consulting fees, speaking fees and/or honoraria from AbbVie, Eli Lilly, Novartis, Pfizer, UCB, Celgene, Sanofi, Regeneron, Merck, Biogen Idec and Janssen, and has served as a paid consultant for investment analysis companies Cowen Group and GLG. CYL, JB and MMH are fulltime employees and shareholders of Eli Lilly and Company. CLS is a former employee and shareholder of Eli Lilly and Company. DT has been a consultant and advisor and has received speaking fees and grants, and served as an investigator in clinical trials for the following companies: AbbVie, Almirall, Amgen, Biogen Idec, BMS, Boehringer Ingelheim, Celgene, Dignity, Dermavant, Eli Lilly, Galapagos, GSK, Galderma, LEO Pharma, Janssen-Cilag, MSD, Novartis, Pfizer and Regeneron.

Patient and public involvement statement This research was done without patient involvement. Patients were not invited to comment on the study design and were not consulted to develop patient relevant outcomes or to interpret the results. Patients were not invited to contribute to the writing or editing of this document for readability or accuracy.

Patient consent for publication Not required.

Provenance and peer review Not commissioned; externally peer reviewed. 
Data availability statement Lilly provides access to all individual participant data collected during the trial, after anonymisation, with the exception of pharmacokinetic or genetic data. Data are available to request 6 months after the indication studied has been approved in the USA and EU and after primary publication acceptance, whichever is later. No expiration date of data requests is currently set once they are made available. Access is provided after a proposal has been approved by an independent review committee identified for this purpose and after receipt of a signed data sharing agreement. Data and documents, including the study protocol, statistical analysis plan, clinical study report and blank or annotated case report forms, will be provided in a secure data sharing environment for up to 2 years per proposal. For details on submitting a request, see the instructions provided at www.clinicalstudydatarequest.com.

Open access This is an open access article distributed in accordance with the Creative Commons Attribution Non Commercial (CC BY-NC 4.0) license, which permits others to distribute, remix, adapt, build upon this work non-commercially, and license their derivative works on different terms, provided the original work is properly cited, appropriate credit is given, any changes made indicated, and the use is non-commercial. See: http://creativecommons.org/licenses/by-nc/4.0/.

\section{REFERENCES}

1 Ritchlin CT, Colbert RA, Gladman DD. Psoriatic arthritis. N Engl J Med 2017:376:957-70

2 Husted JA, Gladman DD, Farewell VT, et al. Health-related quality of life of patients with psoriatic arthritis: a comparison with patients with rheumatoid arthritis. Arthritis Rheum 2001:45:151-8.

3 Kotsis K, Voulgari PV, Tsifetaki N, et al. Anxiety and depressive symptoms and illness perceptions in psoriatic arthritis and associations with physical health-related quality of life. Arthritis Care Res 2012;64:1593-601.

4 Michelsen B, Fiane R, Diamantopoulos AP, et al. A comparison of disease burden in rheumatoid arthritis, psoriatic arthritis and axial spondyloarthritis. PLOS One 2015:10:e0123582.
5 Sokoll KB, Helliwell PS. Comparison of disability and quality of life in rheumatoid and psoriatic arthritis. J Rheumatol 2001;28:1842-6.

6 Genovese MC, Weinblatt ME, Mease PJ, et al. Dual inhibition of tumour necrosis factor and interleukin-17A with ABT-122: open-label long-term extension studies in rheumatoid arthritis or psoriatic arthritis. Rheumatology 2018;57:1972-81.

7 Weiss SC, Kimball AB, Liewehr DJ, et al. Quantifying the harmful effect of psoriasis on health-related quality of life. J Am Acad Dermatol 2002;47:512-8.

8 Mease PJ, van der Heijde D, Ritchlin CT, et al. Ixekizumab, an interleukin-17A specific monoclonal antibody, for the treatment of biologic-naive patients with active psoriatic arthritis: results from the 24-week randomised, double-blind, placebo-controlled and active (adalimumab)-controlled period of the phase III trial SPIRIT-P1. Ann Rheum Dis 2017:76:79-87.

9 Nash P, Kirkham B, Okada M, et al. Ixekizumab for the treatment of patients with active psoriatic arthritis and an inadequate response to tumour necrosis factor inhibitors: results from the 24-week randomised, double-blind, placebo-controlled period of the SPIRIT-P2 phase 3 trial. Lancet 2017;389:2317-27.

10 Fredriksson T, Pettersson U. Severe psoriasis--oral therapy with a new retinoid. Dermatologica 1978;157:238-44.

11 Schoels M, Aletaha D, Funovits J, et al. Application of the DAREA/DAPSA score for assessment of disease activity in psoriatic arthritis. Ann Rheum Dis 2010;69:1441-7.

12 Reilly MC, Zbrozek AS, Dukes EM. The validity and reproducibility of a work productivity and activity impairment instrument. Pharmacoeconomics 1993;4:353-65.

13 Ware JE, Sherbourne CD. The mos 36-item short-form health Survey (SF-36). I. conceptual framework and item selection. Med Care 1992;30:473--83.

14 Gu C. Smoothing Spline ANOVA Models. In: 433. 2 ed. New York: Springer-Verlag, 2013.

15 Kavanaugh A, Antoni C, Krueger GG, et al. Infliximab improves health related quality of life and physical function in patients with psoriatic arthritis. Ann Rheum Dis 2006;65:471-7.

16 Kavanaugh A, McInnes IB, Krueger GG, et al. Patient-reported outcomes and the association with clinical response in patients with active psoriatic arthritis treated with golimumab: findings through 2 years of a phase III, multicenter, randomized, double-blind, placebo-controlled trial. Arthritis Care Res 2013;65:1666-73. 